\title{
CHALLENGES AND EXPERIENCES OF LADY HEALTH WORKERS WORKING IN POLIO CAMPAIGNS IN DISTRICT NOWSHERA, KHYBER PAKHTUNKHWA, PAKISTAN
}

\author{
Shaista Bahar ${ }^{1}$, Rozina Khalid ${ }^{2}$, Shehzad Ali Khan ${ }^{3}$ Naseemullah $^{4}$, Nazish Batool ${ }^{5}$ \\ ${ }^{1,2,3,5}$ Department of Public Health, Health Services Academy Islamabad. \\ ${ }^{4}$ Health department, Government of Khyber Pakhtunkhwa.
}

\begin{abstract}
Background: Lady Health Workers (LHWs) are recruited from the local rural communities under the National Programme for Family Planning. In addition to their assigned duties, they conduct door to door polio vaccination campaigns. However, for the last five years, amid to the security situation in the country Khyber Pakhtunkhwa (KP), Quetta and Karachi, remained the main highest -risk areas for them for polio campaigns.

Methods: We conducted this qualitative study in two union councils of District Nowshera by doing IDIs and FGDs with LHWs who performed their duties in polio campaigns. We used a field guide for interviewing. District coordinator of EPI and two Lady Health Supervisor (LHS) were also interviewed. Interviews were conducted and recorded, the audiotapes were transcribed and categorized on themes and sub themes. Content analysis was carried out. The data was presented in narrative form using summative and verbatim quotes.

Results: There was shortage and insufficient supply of medicines. The second most important issue the LHWs faced was the security. Delay in salary release, no incentives and promotion, community disrespect, administrative constraints, misperceptions regarding polio vaccines and work load were important challenges.

Conclusion: We conclude that the LHWs in both the union councils faced some challenges. Awareness through media is a good option but due to threats to the polio campaigns it is hard to work in these campaigns.
\end{abstract}

Keywords: Community workers, polio, security, developing country.

\section{Introduction}

Polio had existed for thousands of years in certain areas. Major polio epidemics started to appear in the late 19th century in Europe and soon after the United States, and it became one of the most lifetime disability childhood diseases of the 20th century (1).Through good and appreciable effort involving millions of people and billions of doses of oral polio vaccine, the Global Polio Eradication Initiative (GPEI) has interrupted polio transmission in all the countries but still it is endemic in three countries: Pakistan, Nigeria and Afghanistan (2).

The government of Pakistan initiated primary healthcare (PHC) in 1994 to improve access to primary healthcare for women and children and specially the women and children population of rural communities (3). Lady health workers have been recruited from the local communities all over Pakistan under the NPFP, especially in rural areas. In addition, they conduct vaccination campaigns including the $\mathrm{WHO}$-supervised polio campaign (4).

Pakistan launched its Expanded Programme on Immunization (EPI) in 1978 under the guidance and consistent recommendation of the WHO. Currently, the national EPI aims to immunize all children between the ages of 0 and 23 months against few vaccinepreventable diseases (5).When the federal initiative included expanded immunization programme (EPI), some of the EPI's responsibilities were placed on LHWs (6). Lady Health Workers (LHWs) are an important part of the polio campaigns and have vital importance in polio workforce. More than $85 \%$ of the total numbers of LHWs are working in each campaign. They contribute to polio eradication through health education and door-to-door delivery of polio vaccine (7). Critical to the eradication effort in Pakistan almost 106,000 Lady Health Workers (LHWs) and the government health staff who work on vaccination teams are performing their duties in special door-to-door immunization campaigns. But militant groups have been started targeting these vaccinator groups, breaking down the only front line of defense against polio (8).

In December 2012, militant groups murdered approximately 9 polio campaign workers in Pakistan, and this has been continued into 2013 with the death toll now nearing 20 (9). Lady health Workers going door-todoor for delivering polio vaccine have been shot, and 
they have been the targets of bombings at health centers (10). A study conducted in swat valley which is the central northern half of KPK, showed that LHWs faced problems in communicating efficiently with the families due to which a proportion of 0 to $33 \%$ LHWs encountered OPV refusals ranged from 0.5 to $5.7 \%$, as the mother's perceptions that OPV contained birth control or pork and a foreign or central pork against Muslims. Same was the case with injectable vaccines (11). In 2014, around 300,000 children were remain and were not vaccinated in North, South Waziristan and Khyber agency. Due to the search operation in Swat and threats by the Taliban, areas in KPK, Quetta and Karachi, remain the most sensitive and high-risk areas for polio workers. Therefore, fighting against polio has become a challenge for the government and also for the LHWs to perform their duties in polio campaign (12).

\section{Methodology}

A Qualitative study was conducted from October 2014 to January 2015. Field guide was designed and translated into Urdu and Pashto. It was pre tested to identify any possible problem in the translation flow or language of discussion. The field guide was improved after pretesting. Purposive sampling technique was used for collecting data. A total of 31 lady health workers were interviewed in which 7 In-depth interviews (IDI) and 3 focus group discussions (FGD) were conducted. In focus group discussion, 24 LHWs participated. So there were 8 participants in each group discussion. The age of participants were ranging from 22 to 40 years. The district coordinator (DC) and lady health supervisor (LHS) were asked about the performance of lady health workers in polio campaigns and they were asked about lady health workers complaints as well as their performance satisfaction regarding duties in EPI. After collecting the data it was described in MS word and analyzed through thematic analysis.

\section{Results}

The study was conducted in two selected union councils i.e., Akbar Pura and Taru Jabba of Nowshera. FGDs and IDIs were conducted in both union councils with lady health workers working specifically in polio campaign. Luckily there was no polio case reported in District Nowshera. The LHWs were interviewed about the challenges they were facing in performing their duties in door-to-door visits for polio vaccination. In this study, along with LHWs we also interviewed 3 programme officials, one District coordinator of EPI and two lady health supervisors in order to identify and explore their perceptions about what kind of complaints or issues they received from LHWs and to know the actions they have taken to solve the issues. The challenges responded by LHWs working in polio campaign were: No incentives and promotion, Security issues in some areas, community disrespect, irregular and delayed salary, administrative constraints, misperceptions regarding polio vaccines, work load and non-cooperation of polio teams, unavailability of transport facility.
Majority LHWs expressed and reported that they were not promoted or provided with incentives after many years of their job.

"We are facing promotion issues, we are working for many years but still we are not given incentives and we are not promoted yet. "LHW FGD Taru Jabba

Irregular and delayed salary, Administrative constraints, No incentives and promotion were some of the issues related to job dissatisfaction. LHWs performed duties in campaigns but after campaigns they did not get their salary on time.

"We work in campaigns and other programmes but the salary from polio campaigns is always coming late, we did not get salary on time, we got salary after months, sometime we get salary after 6 months, due to which we face many problems at home and it also disturbs our work efficiency" LHW FGD Akbar Pura

Some of the LHWs reported that they faced administrative issues while getting salaries.

"Administration staff is not supportive in case of providing letters and salary checks, we know that we are permanent now but administration staff are not providing letters and salary checks on time"LHW FGD Akbar Pura

Regarding Security issues in some areas due to threats, the LHWs of union council Taru Jabba expressed their problem which was affecting their duties.

" The security condition is not good and I sometime hear that some people were killed who were working in polio campaigns and for a week there is strike from the LHWs side and their families who lost their daughters and sons due to working in the polio campaigns. " LHW IDI Akbar Pura

Few of the LHWs reported disrespect from the community side. Due to threats to the polio campaigns, these campaigns were more highlighted and people were not much cooperative. In such condition, community refusal issues were faced by LHWs.

"Because of the threats, people do not open their doors and we try to communicate with them but they become aggressive" LHW FGD Taru Jabba

The LHWs expressed their concerns about IDPs and Afridi community in their area, who were showing more resistance and most of the refusals regarding polio vaccination.

"When I go door-to-door for administering polio vaccines, people ask questions about repeated campaigns and sometime few of them say, "why not America gives other medicines for free, I don't trust my children's lives with only receiving these few drops of polio vaccines," LHW IDIAkbar Pura

Majority of the LHWs reported that they faced difficulty in regular work because they were not working only in polio campaigns but they were also working with National programme for family planning, Primary health care and other vertical programmes.

"I am married and I have many other responsibilities too, workload is more during polio campaigns, salary is 
less as compared to total work I perform but I can do my job well if work load is reduced. "LHW IDI Akbar Pura

Few of the LHWs expressed their concern about the lack of transport availability.

"My area of working is large, as the villages are in long distances, I face issue of mobility from one area to another, and due to lack of transport I face difficulty to perform my duty on time in campaigns" LHW IDI Taru Jabba

Most of the LHWs were local residents of village. Most of them were graduate few of them were metric pass. The bar graph shows LHWs level of education.

\section{Education level of the respondents}

Figure 1 shows the education level of the LHWs interviewed. Among $31 \mathrm{LHWs}, 38.7 \%$ (twelve in numbers) were metric pass and $51.6 \%$ (sixteen in numbers) were intermediate pass. Only $9.6 \%$ (three in numbers) of the total respondent LHWs were graduates.

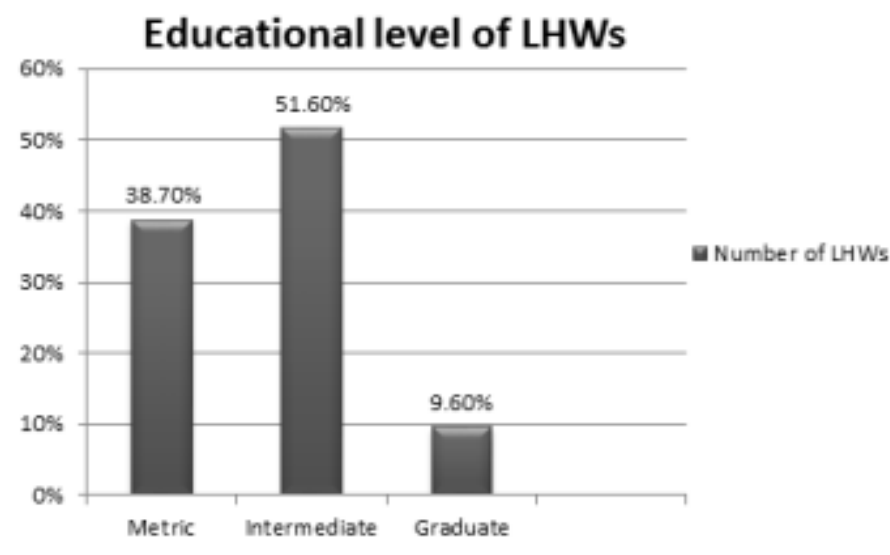

Figure 1. Education level of the LHWs interviewed Satisfaction level of the respondents

Table 1 below details the level of respondents on a scale of not at all satisfied to extremely satisfied. We found that most of the LHWs were either extremely or very satisfied. One of the LHWs was moderately satisfied. Only three of the LHWs were unsatisfied because of various constraints including delayed salary and administrative issues.

Table 1. Satisfaction level of the respondents

\begin{tabular}{|c|c|c|c|c|c|}
\hline $\begin{array}{c}\text { Respondents } \\
\text { views }\end{array}$ & $\begin{array}{c}\text { Not at all } \\
\text { satisfied }\end{array}$ & $\begin{array}{c}\text { Slightly } \\
\text { satisfied }\end{array}$ & $\begin{array}{c}\text { Moderately } \\
\text { satisfied }\end{array}$ & $\begin{array}{c}\text { Very } \\
\text { satisfied }\end{array}$ & $\begin{array}{c}\text { Extremely } \\
\text { satisfied }\end{array}$ \\
\hline $1,2,11,12,14$ & & Ss & & & \\
\hline $3,4,9,10,13,15$ & & & & vs & \\
\hline $5,6,8,16,18,23$ & & & & & Es \\
\hline $7,17,19,21,24$ & & & & & \\
\hline $20,22,25,28,29$ & & & & & \\
\hline $26,27,30$ & $\mathrm{~ns}$ & & & & \\
\hline 31 & & & Ms & & \\
\hline
\end{tabular}

\section{Discussion}

The purpose of the study was to identify and explore the challenges faced by leady health workers in performing their work in polio campaigns and to document their great role as health care providers providing door-todoor services. In District Nowshera the average age of LHWs was between 22 to 38 years. LHWs were working with these vertical programmes including EPI since the inception of the programme. LHWs in district Nowshera joined the programme due to their own interest in the field of health, their educational level was not much different from the other LHWs working in Pakistan. But deficient knowledge of staff in skills still existed. For the success of programme, training should be introduced and capacity building must be developed (13).

A study conducted showed that the performance is negatively affected when the supervision and technical aspect is being avoided. To improve immunization coverage, Lady Health Workers (LHWs) working under the National Program for Family Planning and Primary Health Care (NP for FP \& PHC) can be deputed with vaccinators for better outcome (14).

The LHWs sometime felt overburden due to their responsibilities in other programmes too. They wrote the data about the number of children who get vaccinated but previous studies show that sometime there is problem in the quality and validity of data that might happen due to stress and work burden. This is not only the responsibility of LHWs, there is a lack of deficient knowledge and supervision among the staff responsible for it. It is also reported that in Pakistan the EPI records are not computerized and a study showed the feasibility of a linked database system for immunization (15).

LHWs play a pivotal role in the provision of health care services in door to door visits. They act as a bridge between the health services and the community. These bridging activities include the provision of effective preventive and curative services along with management of community ownership of health related programmes (16).

In our study the bridge is not working properly due to the behavior of the community, deficient cooperation between immunization teams and response of the doctors. The LHWs faces problems due to nonavailability of medicine when women ask about medicines during campaigns and the LHWs are unable to answer them. They sometime don't trust in these campaigns and ask why these are carried out on routine basis as there are other programmes regarding public health but they are not conducted on routine basis.

Due to critical security conditions in the district, they are facing problems specially those who are the only earning members of their family. Their family supports them but when the security condition is not suitable for work then their family does not allow them to work in such condition. Sometime the security staff is not working well as they are also afraid of the threats to polio campaigns so only few of LHWs suggested that rather 
than getting prominent it is better that they should not be provided with security. While mostly were in favour of getting security.

On the other hand the district coordinator of EPI was aware of the problems and challenges faced by the LHWs working in the polio campaigns in their respective areas and they were unable to solve the issue because of the hierarchical structure of the programme, the issues which can be solved at local level in the respective areas of LHWs were ; response or behavior of the community and respect by the religious leaders, awareness by giving fatwas by religious leaders in the community regarding the importance of polio vaccines, significant results were not achieved but still they solved some of the problems regarding the community response.

\section{Conclusion}

In this study it is concluded that the leady health workers in the both union councils faced some challenges, most of the challenges were symmetrical while other issues were specific to the union council. The symmetrical issues were like insufficient supply of medicine, delay in salary and security issues. The issues specific to one union council were response or behavior of the community. For better outcome, remuneration should be provided on time and there should be no delay in salary. Incentives and promotion would be effective for motivation Workload should be reduced and number of teams should be increased. Security must be provided specially in the vaccination points at the respective health care center.

\section{References}

1. Skold. P. From inoculation to vaccination: smallpox in Sweden in the eighteenth and nineteenth centuries, 1996; 50:247-262.

2. Torun SD, Bakirci N. Vaccination coverage and reasons for non-vaccination in a district of Istanbul. BMC Public Health 2006; 6:125.

3. Internal assessment of LHWs programme 2007.NPFP and PHC Islamabad, Pakistan MoHGo; 2008.

4. Yasuyo Osanai R. Increasing access to skilled attendants for making safer home birth: A case of rural Pakistan, Harvard school of public health, takemi programme international.2004-05.

5. Khan A. Lady Health Workers and Social Change in Pakistan. Econ Polit Wkly. 2011;46: 28-31.

6. Khan A. Lady Health Workers and Social Change in Pakistan. Econ Polit Wkly. 2011; 46: 28-31.

7. Government of Islamic Republic of Pakistan (2013) National Emergency Action Plan 2013 For Polio Eradication. Islamabad: GoP.

8. Hasan Q, Bosan AH, Bile KM. A review of EPI progress in Pakistan towards achieving coverage targets: present situation and the way forward. 2010.

9. IED blast injures Iady health worhttp://tribune.com.pk/story/572624/tankkilling-lady-health-worker-shot-dead/. ker (2013). 21 Express Trib. Available: http://tribune.com.pk/story/516158/ied-blastinjures-lady-health-worker/. Accessed 22 March 2013.

10. Tank Killing: Lady Health Worker Shot Dead (2013). Express Trib. Available: Accessed 5 July 2013.

11. Murakami $\mathrm{H}$ et al, ,Refusals of oral polio vaccine in northwestern Pakistan:A qualitative and quantitative study, vaccine, 2014; 32, pages 1382-1387.

12. Jawaid A,(2014) Battling polio.

13. Masud T, Navaratne KV: The Expanded Program on Immunization in Pakistan Recommendations for Improving Performance. Health, Nutrition and Population (HNP) Discussion Paper. Washington, DC: The International Bank for Reconstruction and Development/The World Bank; 2012.

14. Imran S.S., Ramzan M. Maqsood I, Status of immunization of children and factors related partial and non-immunization. Biomedic. 2014; vol.30, Issue 3, p1-4.

15. Challenges in global immunization and the global immunization vision and strategy. Weekly Epidemiological Record.2006-2015; 81, 190194.

16. Closser S, Jooma: why we must provide better support for Pakistan's female frontline health workers. PLoS Med R. 2013; 10 (10). 